\title{
Diabesity Associates with Poor COVID-19 Outcomes among Hospitalized Patients
}

\author{
Zeinab Nikniaz', Mohammad Hossein Somi', Masood Faghih Dinevari ${ }^{1,2, *}$, Ali Taghizadieh ${ }^{3}$, Leila Mokhtari² \\ ${ }^{1}$ Liver and Gastrointestinal Diseases Research Center, ${ }^{2}$ Imam Reza Hospital, and ${ }^{3}$ Tuberculosis and Lung Disease Research Center, Tabriz University of Medical \\ Sciences, Tabriz, Iran
}

Background: Although numerous studies have investigated obesity's negative effect on coronavirus disease 2019 (COVID-19) outcomes, only a limited number focused on this association in diabetic patients. In this study, we analyzed the association between obesity and COVID-19 outcome (death, intensive care unit [ICU] admission, mechanical ventilation needs, quick Sequential Organ Failure Assessment [qSOFA] score, and confusion, urea, respiratory rate, blood pressure [CURB-65] scores) for hospitalized diabetic patients.

Methods: In this prospective hospital-based registry of patients with COVID-19 in East Azerbaijan, Iran, 368 consecutive diabetic patients with COVID-19 were followed from admission until discharge or death. Self-reported weight and height were used to calculate body mass index $\left(\mathrm{kg} / \mathrm{m}^{2}\right)$ upon admission. Our primary endpoint was analyzing obesity and COVID-19 mortality association. Assessing the associations among obesity and disease severity, ICU admission, and mechanical ventilation was our secondary endpoint.

Results: We analyzed data from 317 patients and found no significant difference between obese and nonobese patients regarding frequency of death, invasive mechanical ventilation, ICU admission, CURB-65, or qSOFA scores $(P>0.05)$. After adjusting for confounding factors, obese diabetic COVID-19 patients were 2.72 times more likely to die than non-obese patients. Moreover, ventilator dependence (adjusted odds ratio [aOR], 1.87; $95 \%$ confidence interval $[\mathrm{Cl}], 1.03-4.76$ ) and ICU admission (aOR, 2.41; $95 \% \mathrm{Cl}, 1.11-5.68$ ) odds were significantly higher for obese patients than non-obese patients.

Conclusion: The results of the present study indicated that obesity worsens health outcomes for diabetic COVID-19 patients.

Key words: COVID-19, Death, Diabetes mellitus, Intensive care units, Obesity

Received November 17, 2020

Reviewed December 10, 2020

Accepted February 7, 2021

${ }^{*}$ Corresponding author

Masood Faghih Dinevari

(i)

https://orcid.org/0000-0003-4889-7366

Liver and Gastrointestinal Diseases Research Center, Imam Reza Hospital, Tabriz University of Medical Sciences, Golgasht St, Tabriz, Iran Tel: +98-41-33351688 Fax: +98-41-33351688 E-mail: masood.dinevari@gmail.com

\section{INTRODUCTION}

The coronavirus disease 2019 (COVID-19) outbreak originated in Wuhan, China, spread rapidly, and was declared a global pandemic in March 2020. In Iran, the first official COVID-19 death was February 19, 2020. Between then and August 4, 2020, approximately 312,035 more cases have been diagnosed. ${ }^{1}$ COVID-19 is associated with high morbidity and mortality rates ${ }^{2}$ and a $6.0 \%$ global fatality rate. ${ }^{3}$ In Iran, there is a $24.4 \%$ 30-day cumulative risk for in-hospital mortality ${ }^{4}$ with a $3.6 \%$ average COVID-19 mortality rate. ${ }^{5}$ Different factors affect COVID-19's morbidity and mortality rates including age, sex, obesity, and comorbidities such as diabetes mellitus, hypertension, cardiovascular disease, kidney disease, and liver disease. ${ }^{6}$

After hypertension, diabetes mellitus is the most prevalent comorbid disease affecting COVID-19 patients. $^{7}$ The COVID-19 morbidity rate is significantly higher in diabetic patients than nondiabetic patients. ${ }^{8}$ In this regard, studies have attempted to investigate factors contributing to diabetic patients' poor health outcomes. Thus far, reports show that age and comorbid hypertension are

Copyright (C) 2021 Korean Society for the Study of Obesity

(a) This is an Open Access article distributed under the terms of the Creative Commons Attribution Non-Commercial License (https://creativecommons.org/licenses/by-nc/4.o/) which permits unrestricted non-commercial use, distribution, and reproduction in any medium, provided the original work is properly cited. 
contributors. ${ }^{9}$ Obesity is a risk factor for infectious diseases such as pneumonia, surgical-site infections, nosocomial infections, periodontitis and skin infections. ${ }^{10}$ Numerous studies have also shown obesity's negative effect on COVID-19 severity and critical conditions. ${ }^{3,11,12}$ Mechanisms such as increased proinflammatory cytokines, decreased immunity and decreased lung function may play a role in poor COVID-19 health outcomes among obese patients. ${ }^{13}$

In addition, obesity may contribute to the COVID-19 health outcomes in patients with underlying diseases such as diabetes mellitus. Diabetic patients often have impaired immune function, low-grade chronic systemic inflammation, and impaired lung function. ${ }^{14-16}$ This is similar to the comorbidities observed in obese patients. In this study, we postulated that obese diabetic patients with COVID-19 may have worse disease outcomes than non-obese diabetic patients. There have been few studies on the relationship between obesity and COVID-19 outcomes in diabetic patients. In this study, we analyzed the association between obesity and COVID-19 outcomes (death, intensive care unit [ICU] admission, mechanical ventilation, quick Sequential Organ Failure Assessment [qSOFA] scores, and confusion, urea, respiratory rate [RR], blood pressure [CURB-65] scores) in hospitalized diabetic patients.

\section{METHODS}

Data were obtained from the AzarCoRe (East Azar Covid-19 Registry) study. Briefly, patients were included in this registry if COVID-19 was confirmed by reverse transcription-polymerase chain reaction of throat and nose swab specimens from the upper respiratory tract or clinically diagnosed based on lung imaging like chest computed tomography scans showing ground glass pathognomonic features consistent with coronavirus pneumonia. All registered cases were given a unique code to prevent duplication.

For data collection, a questionnaire that included demographic characteristics, vital signs, drug history, laboratory parameters, COVID-19-related symptoms, medication, and outcomes was designed. We also collected lifestyle information such as smoking and physical activity levels. During anamnesis, we collected information on comorbidity diagnoses. The COVID-19 nurses completed the questionnaires and a trained researcher transferred the information to the statistical software. We ascertained diabetes mellitus status through self-reporting.

The patients were followed until they were discharged. Trained nurses recorded all clinical and laboratory parameters daily. Body mass index (BMI; $\mathrm{kg} / \mathrm{m}^{2}$ ) was calculated using self-reported weight and height upon hospital admission. We considered a person with a BMI higher than $30 \mathrm{~kg} / \mathrm{m}^{2}$ to be obese. In the AzarCoRe, approximately 338 diabetic patients registered at Imam Reza Hospital. Twenty-one patients did not complete the questionnaire's request for anthropometric information or disease outcomes, so we only analyzed data from 317 patients.

Tabriz University of Medical Sciences' Ethics Committee approved this study (Ethics code: IR.TBZMED.REC.1398.1274). Informed consent was obtained from the patients or their next of kin.

\section{Outcomes}

The primary endpoint of this study was analyzing the association between obesity and mortality from COVID-19 after adjusting for demographics and comorbidities in diabetic patients. Assessing the association between obesity and COVID-19 severity using the qSOFA score, the CURB-65 score, ICU admission, and mechanical ventilation at any point were our secondary endpoints. The qSOFA score is a validated ICU mortality prediction score. It helps clinicians identify patients with suspected infections that are at high risk for poor outcomes. ${ }^{17}$ We calculated qSOFA by awarding one point each for the Glasgow Coma Scale $<15, R R \geq 22$, and systolic blood pressure (SBP) $\leq 100$. A qSOFA score $\geq 2$ was used as the cutoff based on a higher risk of mortality. ${ }^{18}$ The CURB65 score was used to evaluate pneumonia severity. ${ }^{19}$ It classifies mortality risk for pneumonia patients. ${ }^{20,21}$ CURB-65 was calculated by awarding 1 point each for Glasgow Coma Scale $<15$, blood urea nitrogen $>19 \mathrm{mg} / \mathrm{dL}, \mathrm{RR} \geq 30, \mathrm{SBP}<90 \mathrm{mmHg}$ or diastolic blood pressure $\leq 60 \mathrm{mmHg}$, and age $\geq 65$ years. A CURB- 65 score $\geq 3$ was used as the cutoff based on a higher risk of mortality. ${ }^{22}$

\section{Statistical analysis}

For statistical analysis, IBM SPSS version 25 (IBM Corp., Armonk, NY, USA) was used. The normality of the data distribution was analyzed by the Kolmogorov-Smirnov test. The quantitative and qualitative values are reported as the mean and frequency (\%), respectively. To compare data between obese and non-obese patients, we 
used the independent test. Between-group comparisons for qualitative data were performed by the chi-square test. Logistic regression was used to analyze univariate and multivariate models. The multivariate model considered demographic, lifestyle, and on-admission clinical factors significant in the univariate model. We adjusted the multivariate model for age, sex, smoking, and comorbidities. For all analyses, a $P$-value $<0.05$ was considered significant.

\section{RESULTS}

The data of 317 diabetic COVID-19 patients were included in the present study. Table 1 shows demographic characteristics and comorbidity prevalence stratified by obesity status. The partici- pants' mean age was $65.09 \pm 13.29$ years and $51.4 \%$ was male. There were significant differences between obese and non-obese participants regarding sex $(P<0.01)$.

Table 2 presents outcome according to BMI. There were no significant differences between obese and non-obese patients regarding the frequency of death, mechanical ventilation, ICU admission, CURB-65 score, or qSOFA score. Table 3 summarizes the COVID-19 outcomes and obesity status logistic regression analyses. There was no significant association between obesity and COVID-19 outcome in the unadjusted model. However, after adjusting for confounding factors (age, sex, smoking, and comorbidities), obese diabetic COVID-19 patients had a 2.72 times higher death rate than non-obese patients. Moreover, ventilator dependence

Table 1. The demographic characteristics of diabetic patients with COVID-19

\begin{tabular}{|c|c|c|c|c|}
\hline Demographic variable & Total $(n=317)$ & Non-obese patient $\left(\mathrm{BMl}<30 \mathrm{~kg} / \mathrm{m}^{2}, \mathrm{n}=241\right)$ & Obese patient (BMl $\geq 30 \mathrm{~kg} / \mathrm{m}^{2}, \mathrm{n}=76$ ) & $P$ \\
\hline Age (yr) & $65.09 \pm 13.29$ & $65.99 \pm 12.97$ & $62.89 \pm 13.93$ & $0.14^{*}$ \\
\hline Sex & & & & $<0.01^{\dagger}$ \\
\hline Male & $163(51.4)$ & $133(55.1)$ & $30(39.5)$ & \\
\hline Female & $155(48.8)$ & $108(44.8)$ & $46(60.5)$ & \\
\hline \multicolumn{5}{|l|}{ Comorbidity } \\
\hline CVD & $111(35.0)$ & $86(35.6)$ & $25(32.8)$ & $0.49^{\dagger}$ \\
\hline Respiratory disease & $48(15.1)$ & $37(15.3)$ & $11(14.4)$ & $0.55^{\dagger}$ \\
\hline HTN & $200(63.1)$ & $151(62.6)$ & $49(64.4)$ & $0.39^{\dagger}$ \\
\hline Kidney disease & $58(16.0)$ & 46 (19.1) & $12(15.8)$ & $0.44^{\dagger}$ \\
\hline Carcinoma & $19(5.9)$ & $14(5.8)$ & $5(6.5)$ & $0.50^{\dagger}$ \\
\hline Liver disease & $8(2.5)$ & $4(1.6)$ & $4(5.2)$ & $0.15^{\dagger}$ \\
\hline Autoimmune disease & $5(1.5)$ & $2(0.8)$ & $3(3.9)$ & $0.21^{\dagger}$ \\
\hline Smoker & $17(5.4)$ & $14(5.8)$ & $3(3.9)$ & $0.43^{\dagger}$ \\
\hline Antidiabetic agent use & & & & $0.34^{\dagger}$ \\
\hline Insulin & 107 (33.7) & $76(31.5)$ & $31(40.7)$ & \\
\hline Oral agent & $196(61.8)$ & $155(64.3)$ & $41(53.9)$ & \\
\hline Combination insulin/oral agent & $14(4.4)$ & $10(4.1)$ & $4(5.2)$ & \\
\hline $\mathrm{SBP}(\mathrm{mmHg})$ & $125.55 \pm 17.26$ & $125.30 \pm 17.01$ & $125.67 \pm 17.68$ & $0.88^{*}$ \\
\hline $\mathrm{FBG}(\mathrm{mg} / \mathrm{dL})$ & $170.40 \pm 26.37$ & $169.30 \pm 23.47$ & $186.70 \pm 24.21$ & $0.07^{*}$ \\
\hline ALT (IU/L) & $25.90 \pm 18.27$ & $24.41 \pm 20.55$ & $26.55 \pm 13.82$ & $0.57^{*}$ \\
\hline AST (IU/L) & $35.93 \pm 12.70$ & $30.32 \pm 11.67$ & $37.96 \pm 14.92$ & $0.04^{*}$ \\
\hline Creatinine (mg/dL) & $1.89 \pm 1.81$ & $1.97 \pm 1.85$ & $1.77 \pm 1.84$ & $0.49^{*}$ \\
\hline hs-CRP & $5.30 \pm 1.28$ & $6.30 \pm 1.41$ & $6.66 \pm 2.73$ & $0.63^{*}$ \\
\hline GCS $<15$ & $105(33.1)$ & $82(34.4)$ & 23 (30.2) & $0.45^{\dagger}$ \\
\hline $\mathrm{RR} \geq 22$ & $60(18.9)$ & $46(19.5)$ & $14(18.4)$ & $0.76^{\dagger}$ \\
\hline $\mathrm{SBP}<100 \mathrm{mmHg}$ & $33(10.7)$ & $21(8.2)$ & $12(15.7)$ & $0.06^{\dagger}$ \\
\hline BUN $>19$ & $197(62.1)$ & $147(60.9)$ & $50(65.7)$ & $0.47^{\dagger}$ \\
\hline
\end{tabular}

Values are presented as mean \pm standard deviation or number $(\%)$.

${ }^{*}$ Independent t-test; ${ }^{\dagger}$ Chi-square test.

COVID-19, coronavirus disease 2019; BMI, body mass index; CVD, cardiovascular disease; HTN, hypertension; SBP, systolic blood pressure; FBG, fasting blood glucose; ALT, alanine amino transferase; AST, aspartate amino transferase; hs-CRP, high sensitive-C reactive protein; GCS, Glasgow Coma Scale; RR, respiratory rate; BUN, blood urea nitrogen. 
Table 2. The frequency of COVID-19 outcomes in diabetic patients

\begin{tabular}{lcccc}
\hline Outcome & $\begin{array}{c}\text { Total } \\
(\mathrm{n}=317)\end{array}$ & $\begin{array}{c}\text { Obese patient } \\
\left(\mathrm{BMl}<30 \mathrm{~kg} / \mathrm{m}^{2},\right. \\
\mathrm{n}=241)\end{array}$ & $\begin{array}{c}\text { Non-obese patient } \\
\left(\mathrm{BMl} \geq 30 \mathrm{~kg} / \mathrm{m}^{2},\right. \\
\mathrm{n}=76)\end{array}$ & $P^{*}$ \\
\hline Death & $67(21.1)$ & $47(19.5)$ & $20(26.3)$ & 0.19 \\
Mechanical ventilation & $71(22.3)$ & $49(20.33)$ & $22(28.9)$ & 0.29 \\
ICU admission & $89(28.07)$ & $69(28.6)$ & $20(26.3)$ & 0.17 \\
CURB-65 score & & & & 0.38 \\
$0-1$ & $76(23.9)$ & $57(23.6)$ & $19(25.0)$ & \\
2 & $117(36.9)$ & $92(38.1)$ & $25(32.8)$ & \\
$3-5$ & $124(39.1)$ & $92(38.1)$ & $32(42.1)$ & \\
qSOFA score & & & & 0.45 \\
0 & $33(10.4)$ & $31(12.8)$ & $2(4.5)$ & \\
1 & $255(80.4)$ & $193(80.08)$ & $62(81.8)$ & \\
2 & $29(9.1)$ & $17(7.05)$ & $12(13.6)$ & \\
\hline
\end{tabular}

Values are presented as number (\%).

${ }^{*}$ Chi-square test.

COVID-19, coronavirus disease 2019; BMI, body mass index; ICU, intensive care unit; CURB-65, confusion, urea, respiratory rate, blood pressure; qSOFA, quick Sequential Organ Failure Assessment.

(adjusted odds ratio [aOR], 1.87; 95\% confidence interval [CI], $1.03-4.76$ ) and ICU admission (aOR, 2.41; 95\% CI, 1.11-5.68) were significantly higher in obese patients than non-obese patients.

\section{DISCUSSION}

Our study shows that mortality, ICU admission, and mechanical ventilation odds for hospitalized diabetic COVID-19 patients are significantly higher for obese patients than non-obese patients. Obesity is a risk factor for severe COVID-19.23 In Iran, obesity is a community health problem affecting $24 \%$ of the Iranian population. ${ }^{24}$ Various studies have shown a significant association between obesity and poor COVID-19 outcomes. ${ }^{23,25,26}$ In a systematic review, Földi et al. ${ }^{25}$ reported that obesity is a significant risk factor for COVID-19 ICU admission and invasive mechanical ventilation. Another systematic review and meta-analysis showed the dose-response association between BMI and COVID-19 mortality and severity. ${ }^{27}$

Our results are likely related to the negative effect of both obesity and diabetes mellitus on immune function, ${ }^{28,29}$ which can result in poor COVID-19 outcomes. The higher inflammatory factors found in both obese and diabetic patients may make them susceptible to poor COVID-19 outcomes. ${ }^{13}$ Obesity causes systemic inflammation $^{30}$ and diabetes mellitus is associated with low-grade
Table 3. Logistic regression analysis of obesity and COVID-19 outcomes in diabetic patients

\begin{tabular}{|c|c|c|c|c|}
\hline Outcome & OR (95\% Cl) & $P$ & $\mathrm{aOR}^{*}(95 \% \mathrm{Cl})$ & $P$ \\
\hline Death & $1.47(0.70-3.04)$ & 0.30 & $2.72(1.13-7.44)$ & 0.01 \\
\hline $\begin{array}{l}\text { Requirement for } \\
\text { mechanical ventilation }\end{array}$ & $1.51(0.72-3.15)$ & 0.26 & $1.87(1.03-4.76)$ & 0.04 \\
\hline ICU admission & $1.27(0.64-2.53)$ & 0.48 & $2.41(1.11-5.68)$ & 0.03 \\
\hline CURB-65 & $1.31(0.60-2.85)$ & 0.48 & $1.68(0.32-4.57)$ & 0.57 \\
\hline qSOFA & $2.12(0.66-6.72)$ & 0.20 & $1.47(0.33-10.72)$ & 0.23 \\
\hline
\end{tabular}

Dependent variables: death, mechanical ventilation, ICU admission, CURB-65 score, qSOFA score; Independent variable: obesity status (BMl $\left.>30 \mathrm{~kg} / \mathrm{m}^{2}\right)$.

${ }^{*}$ Adjusted OR for age, sex, smoking status, comorbidities (CVD, respiratory diseases, hypertension, kidney diseases, carcinoma, liver diseases, and autoimmune diseases), glucose concentration and hs-CRP.

COVID-19, coronavirus disease 2019; OR, odds ratio; Cl, confidence interval; aOR, adjusted OR; ICU, intensive care unit; CURB-65, confusion, urea, respiratory rate, blood pressure; qSOFA, quick Sequential Organ Failure Assessment; CVD, cardiovascular disease; hs-CRP, high sensitive-C reactive protein.

chronic systemic inflammation. ${ }^{31,32}$ These two conditions may synergically affect COVID-19 outcomes. ${ }^{33,34}$ A cytokine storm immune response may cause multiorgan failure. ${ }^{3}$ Lung mechanics may also play a significant role in the link between obesity and $\mathrm{CO}$ VID-19 outcomes in diabetic patients. Earlier studies indicate that obesity is associated with poor mechanical ventilation due to limiting diaphragm and chest wall movement. ${ }^{35,36}$ Diabetes mellitus also affects lung function. ${ }^{14,15}$ These two comorbid conditions (obesity and diabetes mellitus) could result in impaired lung function. Moreover, both obesity and diabetes mellitus are associated with increased plasminogen activator inhibitor-1 levels, which increases COVID-19 virulence, ${ }^{16,37}$ and increased reactive oxygen species levels and hypoxia-inducible factor $1 \alpha$ activation, which sustains severe acute respiratory syndrome coronavirus 2 (SARS-CoV-2) replication. ${ }^{13,38-40}$

This study was limited by the small number of patients with simultaneous diabetes mellitus and COVID-19. Moreover, we used self-reported height and weight for BMI calculations. Studies have shown, however, that BMI computed from self-reported weight and height is a valid measure in men and women across different sociodemographic groups. This study's strengths include its prospective nature and the large number of confounding factors analyzed. In conclusion, our results support the hypothesis that obesity is a risk factor for poor health outcomes in diabetic COVID-19 patients. Further studies with larger sample sizes and measured anthropometric indices are needed to confirm these results. 


\section{CONFLICTS OF INTEREST}

The authors declare no conflict of interest.

\section{ACKNOWLEDGMENTS}

This work was supported by a grant from Tabriz University of Medical Sciences (grant no. 65162).

\section{AUTHOR CONTRIBUTIONS}

Study concept and design: MHS, ZN, MFD; acquisition of data: LM, ZN, AT; analysis and interpretation of data: ZN, MFD, MHS, AT; drafting of the manuscript: $\mathrm{ZN}$; critical revision of the manuscript: ZN, MHS, MFD; statistical analysis: ZN; obtained funding: MHS; administrative, technical, or material support: MFD; and study supervision: MHS.

\section{REFERENCES}

1. Worldometer. Coronavirus update [Internet]. Worldometer; 2020 [cited $2020 \mathrm{Jul}$ 12]. Available from: https://www.worldometers.info/coronavirus/\#countries

2. Adhikari SP, Meng S, Wu YJ, Mao YP, Ye RX, Wang QZ, et al. Epidemiology, causes, clinical manifestation and diagnosis, prevention and control of coronavirus disease (COVID-19) during the early outbreak period: a scoping review. Infect Dis Poverty 2020;9:29.

3. Lim S, Shin SM, Nam GE, Jung CH, Koo BK. Proper management of people with obesity during the COVID-19 pandemic. J Obes Metab Syndr 2020;29:84-98.

4. Jalili M, Payandemehr P, Saghaei A, Sari HN, Safikhani H, Kolivand P. Characteristics and mortality of hospitalized patients with COVID-19 in Iran: a national retrospective cohort study. Ann Intern Med 2021;174:125-7.

5. Baber S. Average mortality rate of COVID-19 in Iran. Preprints 2020050161 [Preprint]. 2020 [cited 2020 Jul 12]. Available from: https://doi.org/10.20944/preprints202005.0161.v1

6. Wu C, Chen X, Cai Y, Xia J, Zhou X, Xu S, et al. Risk factors associated with acute respiratory distress syndrome and death in patients with coronavirus disease 2019 pneumonia in $\mathrm{Wu}-$ han, China. JAMA Intern Med 2020;180:934-43.

7. Yang J, Zheng Y, Gou X, Pu K, Chen Z, Guo Q, et al. Prevalence of comorbidities and its effects in patients infected with SARS-CoV-2: a systematic review and meta-analysis. Int J Infect Dis 2020;94:91-5.

8. Roncon L, Zuin M, Rigatelli G, Zuliani G. Diabetic patients with COVID-19 infection are at higher risk of ICU admission and poor short-term outcome. J Clin Virol 2020;127:104354.

9. Shi Q, Zhang X, Jiang F, Zhang X, Hu N, Bimu C, et al. clinical characteristics and risk factors for mortality of COVID-19 patients with diabetes in Wuhan, China: a two-center, retrospective study. Diabetes Care 2020;43:1382-91.

10. Steiropoulos P. Obesity and pneumonia: a complex relationship. Pneumon 2014;27:291-2.

11. Zhou Y, Yang Q, Chi J, Dong B, Lv W, Shen L, et al. Comorbidities and the risk of severe or fatal outcomes associated with coronavirus disease 2019: a systematic review and metaanalysis. Int J Infect Dis 2020;99:47-56.

12. Razieh C, Zaccardi F, Davies MJ, Khunti K, Yates T. Body mass index and the risk of COVID-19 across ethnic groups: analysis of UK Biobank. Diabetes Obes Metab 2020;22:1953-4.

13. Lim S, Bae JH, Kwon HS, Nauck MA. COVID-19 and diabetes mellitus: from pathophysiology to clinical management. Nat Rev Endocrinol 2021;17:11-30.

14. Niranjan V, McBrayer DG, Ramirez LC, Raskin P, Hsia CC. Glycemic control and cardiopulmonary function in patients with insulin-dependent diabetes mellitus. Am J Med 1997; 103:504-13.

15. Ramirez LC, Dal Nogare A, Hsia C, Arauz C, Butt I, Strowig $\mathrm{SM}$, et al. Relationship between diabetes control and pulmonary function in insulin-dependent diabetes mellitus. Am J Med 1991;91:371-6.

16. Yarmolinsky J, Bordin Barbieri N, Weinmann T, Ziegelmann PK, Duncan BB, Inês Schmidt M. Plasminogen activator inhibitor- 1 and type 2 diabetes: a systematic review and metaanalysis of observational studies. Sci Rep 2016;6:17714.

17. Canet E, Taylor DM, Khor R, Krishnan V, Bellomo R. qSOFA as predictor of mortality and prolonged ICU admission in emergency department patients with suspected infection. J 
Crit Care 2018;48:118-23.

18. Seymour CW, Liu VX, Iwashyna TJ, Brunkhorst FM, Rea TD, Scherag A, et al. Assessment of clinical criteria for sepsis: for the third international consensus definitions for sepsis and septic shock (Sepsis-3). JAMA 2016;315:762-74.

19. Karmakar G, Wilsher M. Use of the 'CURB 65' score in hospital practice. Intern Med J 2010;40:828-32.

20. Ewig S, de Roux A, Bauer T, García E, Mensa J, Niederman M, et al. Validation of predictive rules and indices of severity for community acquired pneumonia. Thorax 2004;59:421-7.

21. Aujesky D, Auble TE, Yealy DM, Stone RA, Obrosky DS, Meehan TP, et al. Prospective comparison of three validated prediction rules for prognosis in community-acquired pneumonia. Am J Med 2005;118:384-92.

22. Chang CL, Sullivan GD, Karalus NC, Mills GD, McLachlan JD, Hancox RJ. Predicting early mortality in acute exacerbation of chronic obstructive pulmonary disease using the CURB65 score. Respirology 2011;16:146-51.

23. Palaiodimos L, Kokkinidis DG, Li W, Karamanis D, Ognibene J, Arora S, et al. Severe obesity, increasing age and male sex are independently associated with worse in-hospital outcomes, and higher in-hospital mortality, in a cohort of patients with COVID-19 in the Bronx, New York. Metabolism 2020;108: 154262.

24. Tabrizi JS, Sadeghi-Bazargani H, Farahbakhsh M, Nikniaz L, Nikniaz Z. Prevalence and associated factors of overweight or obesity and abdominal obesity in Iranian population: a population-based study of northwestern Iran. Iran J Public Health 2018;47:1583-92.

25. Földi M, Farkas N, Kiss S, Zádori N, Váncsa S, Szakó L, et al. Obesity is a risk factor for developing critical condition in COVID-19 patients: a systematic review and meta-analysis. Obes Rev 2020;21:e13095.

26. Yang J, Hu J, Zhu C. Obesity aggravates COVID-19: a systematic review and meta-analysis. J Med Virol 2021;93:257-61.

27. Pranata R, Lim MA, Yonas E, Vania R, Lukito AA, Siswanto $\mathrm{BB}$, et al. Body mass index and outcome in patients with $\mathrm{CO}$ VID-19: a dose-response meta-analysis. Diabetes Metab 2021; 47:101178.

28. Nave H, Beutel G, Kielstein JT. Obesity-related immunodefi- ciency in patients with pandemic influenza H1N1. Lancet Infect Dis $2011 ; 11: 14-5$.

29. Huttunen R, Syrjänen J. Obesity and the outcome of infection. Lancet Infect Dis 2010;10:442-3.

30. DeBoer MD. Obesity, systemic inflammation, and increased risk for cardiovascular disease and diabetes among adolescents: a need for screening tools to target interventions. Nutrition 2013;29:379-86.

31. Duncan BB, Schmidt MI. The epidemiology of low-grade chronic systemic inflammation and type 2 diabetes. Diabetes Technol Ther 2006;8:7-17.

32. Alexandraki KI, Piperi C, Ziakas PD, Apostolopoulos NV, Makrilakis K, Syriou V, et al. Cytokine secretion in long-standing diabetes mellitus type 1 and 2: associations with low-grade systemic inflammation. J Clin Immunol 2008;28:314-21.

33. Fabbri LM, Rabe KF. From COPD to chronic systemic inflammatory syndrome? Lancet 2007;370:797-9.

34. Magnussen H, Watz H. Systemic inflammation in chronic obstructive pulmonary disease and asthma: relation with comorbidities. Proc Am Thorac Soc 2009;6:648-51.

35. Dixon AE, Peters U. The effect of obesity on lung function. Expert Rev Respir Med 2018;12:755-67.

36. De Jong A, Verzilli D, Jaber S. ARDS in obese patients: specificities and management. Crit Care 2019;23:74.

37. Hassanin AA, Elhusien AK, Osman AM. Does obesity affect the plasma level of plasminogen activator inhibitor-1? And does CO2 pneumoperitoneum affect it? Egypt J Anaesth 2013; 29:203-6.

38. Codo AC, Davanzo GG, Monteiro LB, de Souza GF, Muraro SP, Virgilio-da-Silva JV, et al. Elevated glucose levels favor SARS-CoV-2 infection and monocyte response through a HIF-1 $\alpha$ /glycolysis-dependent axis. Cell Metab 2020;32:43746.e5.

39. Ban JJ, Ruthenborg RJ, Cho KW, Kim JW. Regulation of obesity and insulin resistance by hypoxia-inducible factors. Hypoxia (Auckl) 2014;2:171-83.

40. Mohanty P, Hamouda W, Garg R, Aljada A, Ghanim H, Dandona P. Glucose challenge stimulates reactive oxygen species (ROS) generation by leucocytes. J Clin Endocrinol Metab 2000;85:2970-3. 